\title{
Solitary eccrine syringofibroadenoma - Case Report*
}

\author{
Caroline Bertolini Bottino ${ }^{1}$ \\ Flávio Rezende Gomes ${ }^{1}$ \\ Ricardo Barbosa Lima ${ }^{1}$
}

\author{
Tais Ferreira Guimarães ${ }^{1}$ \\ Antonio Macedo D'Acri ${ }^{1}$ \\ Carlos José Martins ${ }^{1}$
}

DOI: http:/ / dx.doi.org/ 10.1590/ abd1806-4841.20153802

\begin{abstract}
A bstract: Eccrine syringofibroadenoma is a rare benign adnexal neoplasm derived from cells of the acrosyringium of eccrine sweat glands. ESFA usually manifests as a solitary nodule on the extremities of elderly patients, but it may also present as papules, nodules or plaques. Its clinical appearance is nonspecific and malignant neoplasms should beconsidered in the differential diagnosis. However, histopathological findings are typical. The main treatment is surgical excision. In order to illustrate a typical presentation of the tumor, we report a case of solitary eccrine syringofibroadenoma, including the surgical treatment used and its result.
\end{abstract}

Keywords: Eccrine glands; Skin neoplasms; Surgical flaps

\section{INTRODUCTION}

Eccrine syringofibroadenoma (ESFA) is a rare neoplasm considered to originate from the excretory portion of eccrine sweat glands. It was first described by Mascaro in $1963 .{ }^{1}$ The clinical appearance of ESFA varies considerably and may include multiple papules, erythematous plaques or a solitary nodule. ESFA is classified into five subtypes according to the clinical presentation. However, its histopathological appearance is peculiar and common to all subtypes. ${ }^{2}$ Solitary ESFA is the most common subtype. In order to illustratea typical presentation of the tumor, we report here a case of solitary eccrine syringofibroadenoma, including the surgical treatment used and its result.

\section{CASE REPORT}

A 81-year-old white female patient had had a painful tumor at the lateral malleolus of the right ankle for three years. Physical examination revealed an erythematous tumor with a small central ulceration on the right lateral malleolus (Figures 1 and 2). The following hypotheses were formulated: cutaneous annex tumor, fibrosarcoma, schwannoma, cutaneous lymphoma, basal cell carcinoma and squamous cell carcinoma. Next, a lesion biopsy was performed.

Histopathology showed epidermis-derived, intertwined epithelial cords, ending in thin projections. Some of these projections had a typical 'crab claw' appearance. Between these cords, a rich fibrovascular stroma is present (Figure 3). Light formations of the eccrine ducts were identified within some of the cords (Figure 4).

\footnotetext{
Received on 27.06.2014.

A pproved by theAdvisory Board and accepted for publication on 04.08.2014

* Study conducted at the Dermatology Service of the Hospital Universitário Gaffrée e Guinle da Universidade Federal do Estado do Rio de Janeiro (HUGGUNIRIO) - Rio deJaneiro (RJ), Brazil.

Financial Support: None.

Conflict of Interest: None.

1 Universidade Federal do Estado do Rio de Janeiro (UNIRIO) - Rio deJaneiro (RJ), Brazil.
}

(O2015 by A nais Brasileiros de Dermatologia 


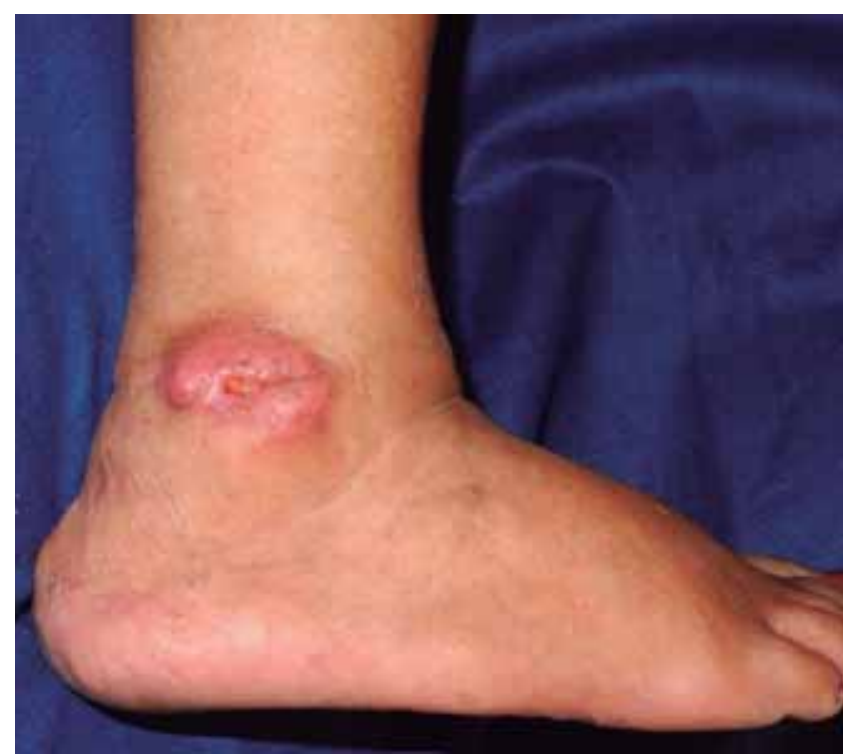

FiguRE 1: Erythematous tumor with a small central ulceration on the right lateral malleolus

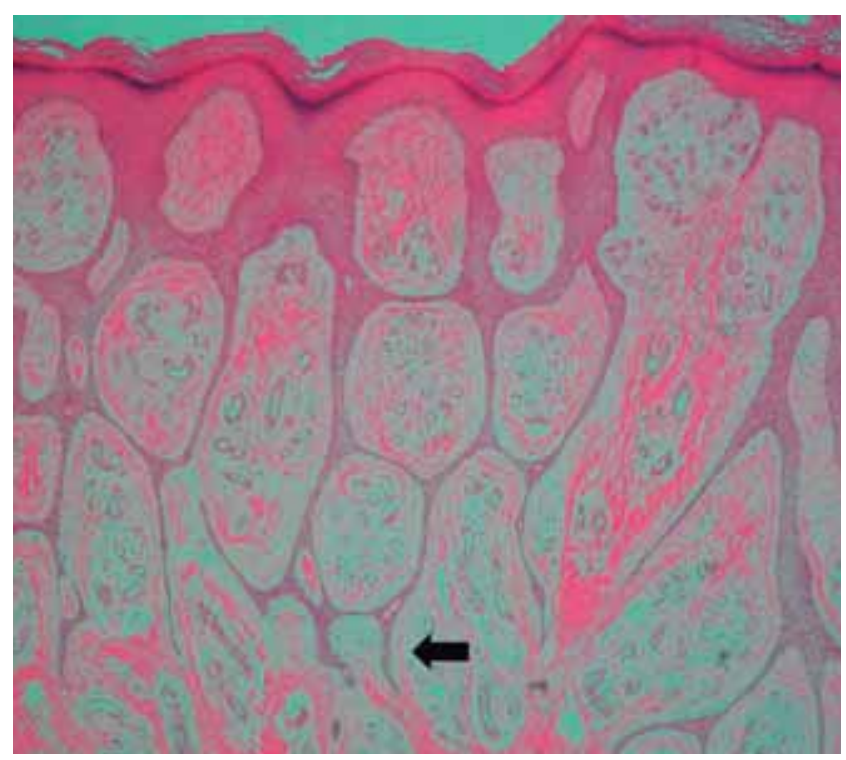

Figure 3: Histopathology showing epidermis-derived, intertwined epithelial cords, ending in thin projections. Some of these projections have a typical 'crab claw' appearance (arrow). Between the cords, a rich fibrovascular stroma was present. (HE, 40x)

The patient was referred to the plastic surgery service, where surgical excision and reconstruction by a reverse-flow supramalleolar flap were done (Figure 5). Three months postoperatively, the patient was completely recovered (Figure 6).

\section{DISQUSSION}

ESFA predominantly affects the elderly, between the seventh and eighth decades of life. The

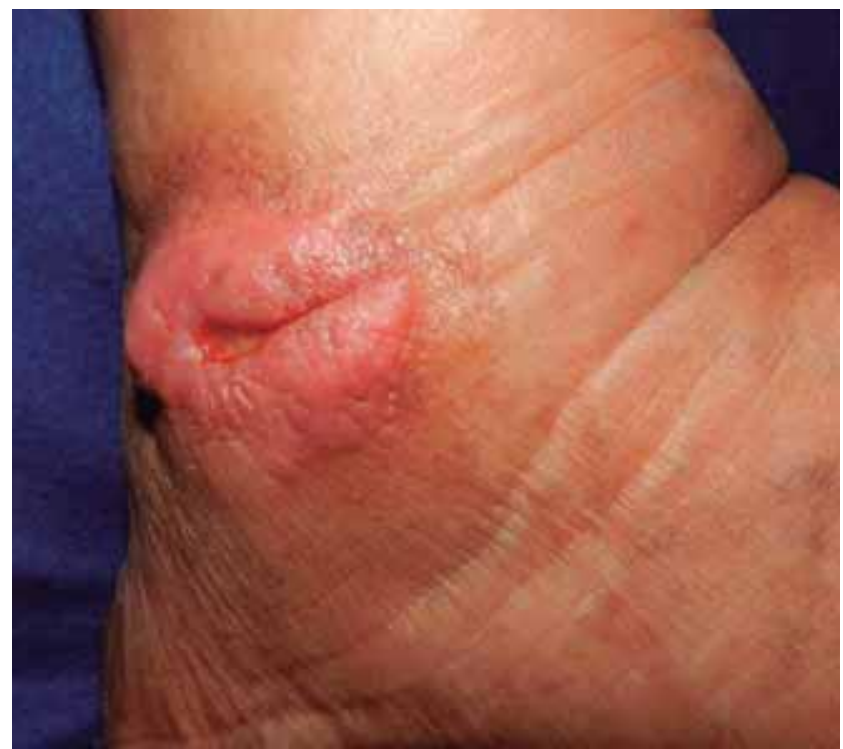

FIgURE 2: Tumor in greater detail, showing its granular surface and ill-defined edges.

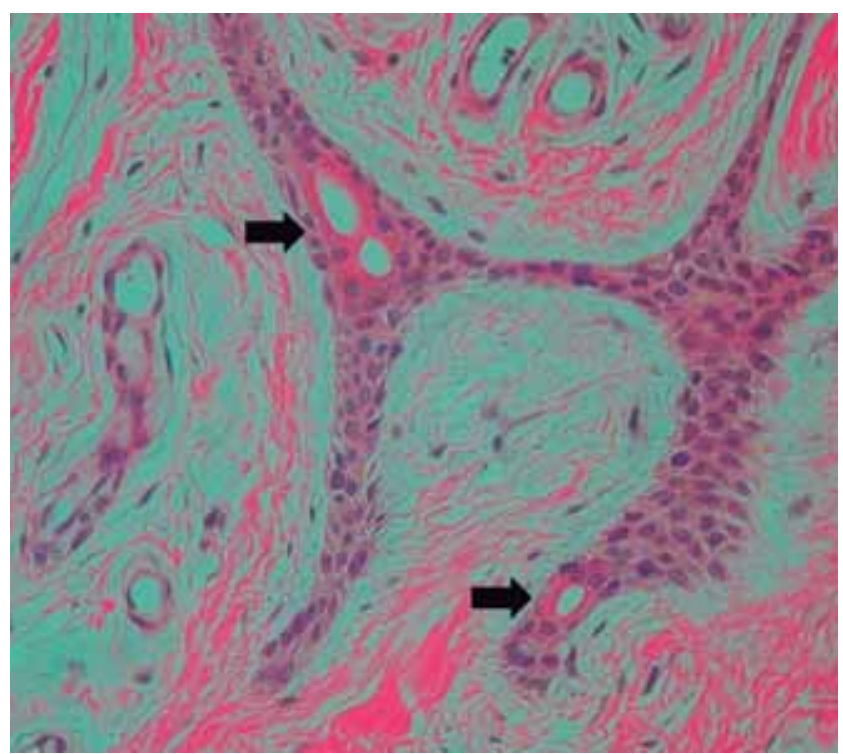

FIGURE 4: Light formations of the eccrine ducts were identified within some of the cords (arrows). (HE, 200x)

distribution of lesions is wide and includes face, back, abdomen, buttocks, extremities and, rarely, the nails. ${ }^{3}$

It is classified into five subtypes according to its clinical presentation: (i) solitary ESFA, a single, non-hereditary, verrucous nodule in elderly patients; (ii) multiple ESFA with Schopf syndrome (an anhidrotic ectodermal dysplasia with hydrocystomas of the eyelids, hypotrichosis, hypodontia and nail abnormalities); (iii) multiple ESFA without cutaneous 


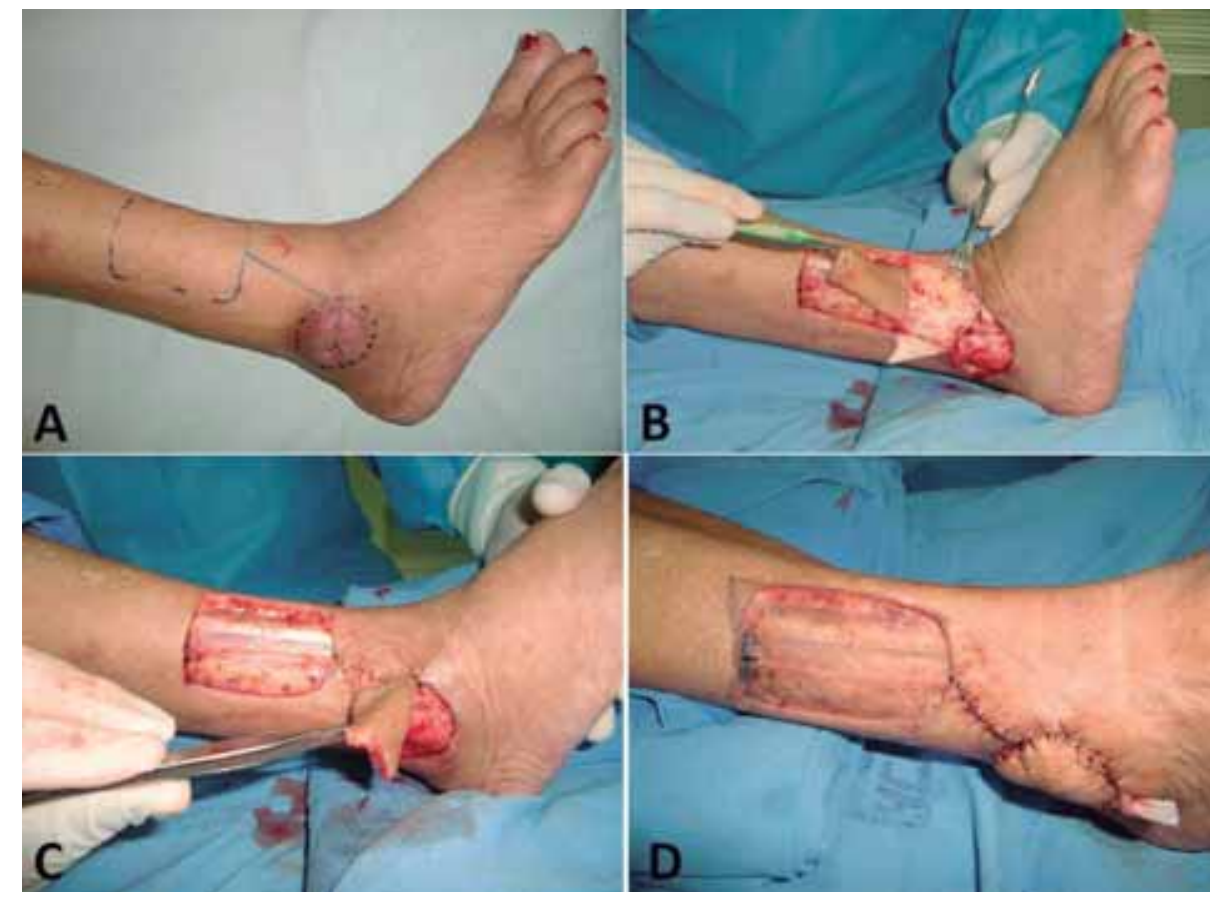

FiguRE 5: A) schematic drawing of the reverse-flow supramalleolar flap, B) the making of the flap according to the surgical plan, $\mathbf{C}$ ) rotation of theflap for coverage of the surgical wound, D) partial skin graft coverage of the flap donor site

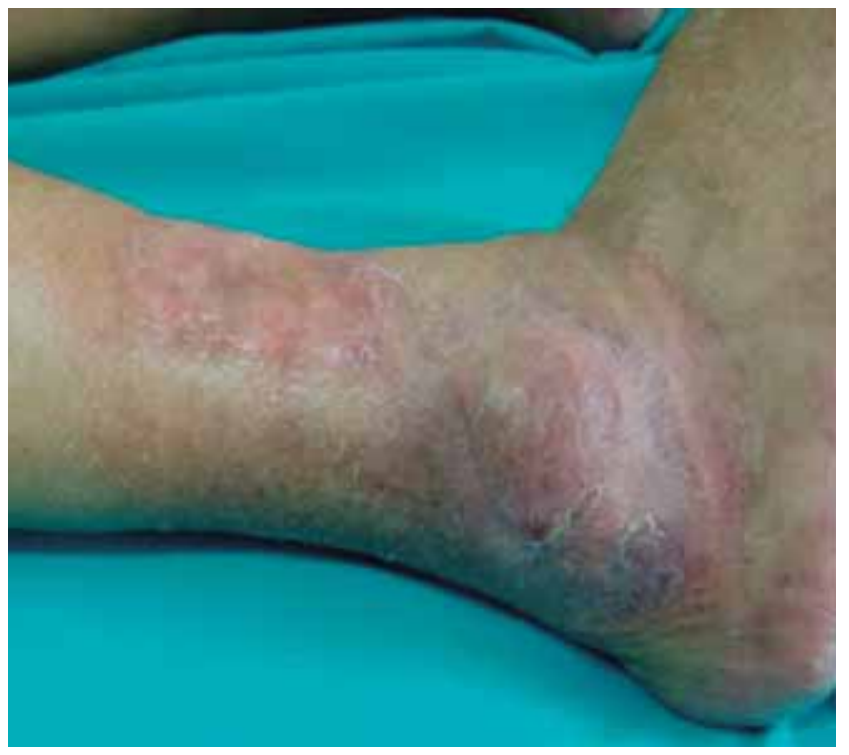

FIGURE 6: result observed three months postoperatively

findings, also called syringofibroadenomatosis; (iiii) Nonfamilial unilateral linear ESFA, also referred to as nevoid ESFA, and (iiiii) reactive ESFA, associated with inflammatory or neoplastic dermatoses, such as erosive lichen planus, bullous pemphigoid, burn scar, squamous cell carcinoma and chronic diabetic foot ulcer. 2,4,5 The case reported here was classified as solitary ESFA, because it was a single lesion on one of the extremities of an elderly patient.

Histopathology is characterized by anastomosing epithelial cords and columns, surrounded by abundant fibrous tissue. Some of these cords have tubular lights in their interior. The epidermis shows long, thin projections, with confluent terminations and a peculiar appearance, similar to crab claws. ${ }^{5}$ The tumor is usually limited to the papillary dermis. ${ }^{6}$

The treatment of choice is surgical excision. Other rarely reported treatments are: cryotherapy, curettage, electrodessication, laser and radiotherapy, with variable patient outcomes. ${ }^{7}$ In the case reported here, we opted for a reconstruction by a reverseflow supramalleolar flap because the tumor was bulky and located in an extremity, which makes the reconstruction of the surgical defect difficult, due to poor skin mobility. Furthermore, the use of the flap promotes better coverage of the area and provides a better protection to the bone surface, given that the lateral malleolus is an area that is highly exposed to trauma. Primary closure with a graft would result in a very thin protective coating. Other flaps used for reconstruction of this region are very thick, which makes wearing of some footwear difficult. In addition, they have an unaesthetic appearance. $^{8}$

Complications include the association with squamous cell carcinoma and malignant transformation into syringofibrocarcinoma and eccrine porocarcinoma. ${ }^{4,9,10}$

The aim of this paper was to report a characteristic presentation of solitary ESFA, including the good results of surgical treatment. $\square$ 


\section{Erratum}

A mistake was made in article Bottino CB, Guimarães TF, Gomes FR, D'A cri AM, Lima RB, Martins CJ. Solitary eccrine syringofi broadenoma: a case report. An Bras Dermatol. 2015;90(3 Suppl 1):S235-8.

Image 2 was switched for image 3 and vice-versa. Figure 2 should show the image of a skin lesion (ankle nodule) and Figure 3 should show the image of the histopathological exam. The legends are correct.

\section{REFERENCES}

1. Mascaró JM. Considérations sur les tumeurs fibro-épithéliales: le syringofibradénome eccrine. Ann Dermatol Syphiligr. 1963;90:143-53.

2. Ichikawa T, Saida T. Solitary eccrine syringofibroadenoma. J Dermatol. 2003;30:853-4.

3. Bothale KA, Mahore SD. Solitary eccrine syringofibroadenoma. Indian J Dermatol Venereol Leprol. 2008;74:518-9.

4. Andrade AC, Vieira DC, Harris OM, Pithon MM. Clouston syndrome associated with eccrine syringofibroadenoma. An Bras Dermatol. 2014;89:504-6.

5. Sobania LRS, Barreto AW, Kanasiro T, Bovo D, Fillus Neto J. Ecrine syringofebroadenoma: report of case. An Bras Dermatol. 1994;69:491-3.

6. Kim JY, Kim YC, Lee ES. Solitary eccrine syringofibroadenoma with prominent plasma cell infiltration. J Dermatol. 2007;34:138-41.

7. Morganti AG, Martone FR, Macchia G, Carbone A, Massi G, De Ninno M, et al. Eccrine syringofibroadenoma radiation treatment of an unusual presentation. Dermatol Ther. 2010;23:S20-3

8. Batista, J C. Retalho supramaleolar de fluxo reverso: aplicações clínicas. Rev Bras Cir Plast. 2011;26: 140-6

9. Katane M, Akiyama M, Ohnishi T, Watanabe S, Matsuo I. Carcinomatous transformation of eccrine syringofibroadenoma. J Cutan Pathol. 2003;30:211-4.

10. Bjarke T, Ternesten-Bratel A, Hedblad M, Rausing A. Carcinoma and eccrine syringofibroadenoma: a report of five cases. J Cutan Pathol. 2003;30:382-92.
M AILIN G ADDRESS:

Caroline Bertolini Bottino

Rua M ariz e Barros, 775

20.270-004 - Rio de Janeiro - RJ

Brazil

E-mail: carolfbertolini@gmail.com

H ow to cite this article: Bottino CB, Guimarães TF, Gomes FR, D'A cri AM, Lima RB, Martins CJ . Solitary eccrine syringofibroadenoma: a Case Report. An Bras Dermatol. 2015;90(3 Suppl 1):S235-8. 